\title{
Invasive species in a confined environment: Reindeer population in the Pribilof Islands
}

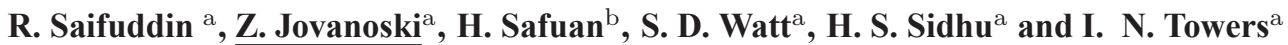

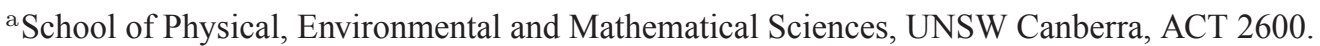 \\ ${ }^{\mathrm{b}}$ Mathematics and Statistics Department, Faculty of Science, Technology and Human Development, \\ Universiti Tun Hussein Onn Malaysia, 86400 Batu Pahat, Johor, Malaysia \\ Email: z.jovanoski@adfa.edu.au
}

\begin{abstract}
The plight of the reindeer population on the Pribilof Islands, Bering Sea, is an interesting example of resource depletion and population collapse. To U.S. government officials, the abundance of lichen on the Pribilof Islands, together with the absence of large grazing animals, and the lack of natural predators appeared ideal conditions for the introduction of reindeer in 1911. Once introduced, the reindeer population grew rapidly followed by a precipitous decline, with very few remaining by 1951. It is generally believed that grazing pressure by the reindeer in combination with markedly warmer and drier climatic conditions caused a rapid and sustained reduction of lichen. We use a variant of the Lotka-Volterra model and apply it to available data to model the reindeer population in response to changes in the availability of lichen.
\end{abstract}

Keywords: Invasive species, predator-prey model, population dynamics 


\section{INTRODUCTION}

Invasive species along with its population dynamics in a native habitat is now considered as one of the most crucial issues of global environmental change (Vitousek et al. 1996). The impact of introduction of invasive species to native habitat is of a major concern among ecologists (Pejchar \& Mooney 2009, Charles \& Dukes 2007, Elton 2000, Rhymer \& Simberloff 1996). Invasive species do not only have damaging economic impacts but also have long term pernicious consequences for biodiversity (Holmes et al. 2009, Stein et al. 2000, Williamson 1996). The introduction of invasive species has a devastating effects on ecological system and it is considered one of the fundamental causes of animal extinction (Clavero \& García-Berthou 2005). The study of invasive species impact has turned into a major multidisciplinary research area involving ecologists, biologists, mathematicians, conservationists and other researchers (Sakai et al. 2001).

In many cases human interactions, either direct or indirect, are involved in the introduction of invasive species to long-distant habitats for either economic or social purposes (Sakai et al. 2001). The introduction of reindeer to St. George Island (part of the Pribilof Islands) was no exception (Scheffer 1951). In 1911, 15 reindeer were introduced to St. George Island to supplement local demand for meat during the seal fur industry. The reindeer however were only lightly harvested (Scheffer 1951). The population dynamics of the reindeer herd was studied by Huzimura \& Matsuyama (1999). Their model was based on a logistic differential equation coupled to an another differential equation representing the instantaneous carrying-capacity. In this paper, a variant of the classic Lotka-Volterra model is used to describe the population dynamics of the reindeer.

\section{MODEL DESCRIPTION}

Before 1910, there were no reindeer on St. George Island, there was however an abundance of lichen. Fifteen reindeer were introduced to St. George Island in 1911 (Scheffer 1951). Figure 1 shows the annual count of reindeer until 1949 except for the years 1942, 1943 and 1944. St. George Island is isolated from other land masses thus confining the introduced reindeer herd. The abundance of lichen and the absence of natural predators on the island resulted in an increase in the reindeer population (Klein \& Shulski 2011). The number of reindeer initially grew quite quickly, reaching 222 reindeer in the space of 11 years. After this population peak, the herd experienced a sustained decline possibly due to over exploitation of the lichen resources. Thus the population dynamics of the reindeer on St. George Island makes an interesting data set to develop models for a confined region with a limited resource.

\subsection{Previous Model}

A first attempt to model the population of the reindeer on St.George Island was by Huzimura \& Matsuyama (1999) (H-M model). The model was based on a logistic-type growth model for the reindeer population, $N(t)$, coupled to the environmental carrying-capacity, $K(t)$,

$$
\begin{aligned}
& \frac{d N}{d t}=a N(t)\left(1-\frac{N(t)}{K(t)}\right) \\
& \frac{d K}{d t}=-b N(t) .
\end{aligned}
$$

In this model the carrying-capacity is used as a proxy variable to describe the state of the environment, in this case the abundance of lichen on the island. The parameter $a$ denotes the intrinsic growth rate of the reindeer whereas $b$ denotes the decay rate of carrying-capacity.

Solving the system of equations (1) and (2) leads to the exact solution for $N(t)$,

$$
N(t)=N_{0} \exp (a t)\left[1-\frac{1}{a}(a-b) \frac{N_{0}}{K_{0}}(1-\exp (a t))\right]^{a /(b-a)}
$$

where $N_{0}$ and $K_{0}$ are the initial reindeer population and carrying-capacity, respectively.

Fitting equation (3) to the data set, Huzimura \& Matsuyama (1999) used a direct search optimization (DSO) method for the three unknown parameters $a, b$ and $K_{0}$, obtaining $a=0.469$ per year, $b=0.0839$ per year and $K_{0}=229$ individuals. The fitted curve is shown in Figure 1. In the H-M model, the initial carrying-capacity was given by $K_{0}=c L_{0}$ with an estimated initial lichen biomass, $L_{0}=4460$ ton, and the estimated nutritional efficiency parameter $c=0.0512$ individual/ton, resulting in an initial carrying-capacity of $K_{0}=229$ reindeer. 


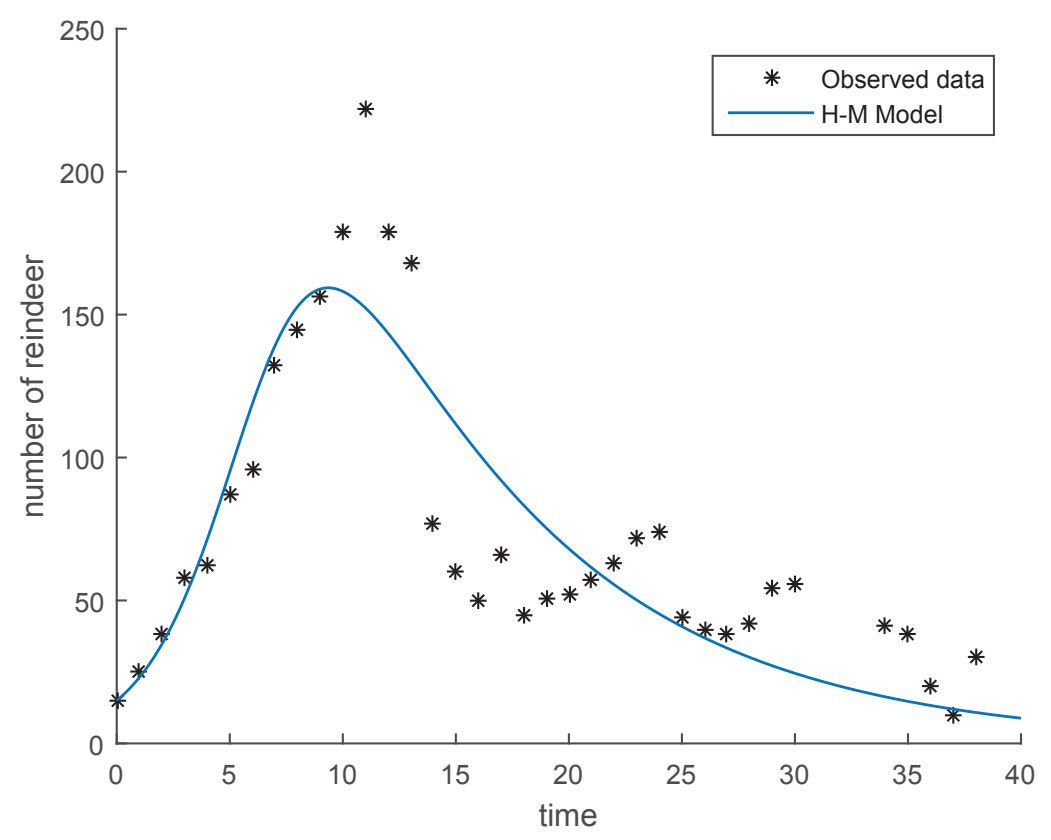

Figure 1. The optimal fitted solution based on the H-M model (Huzimura \& Matsuyama 1999) to the reindeer population.

The decay rate of the carrying-capacity was estimated from $b=1.64 c=0.0839$ with units per year, where 1.64 an observed estimate of the consumption rate of lichen by a single reindeer per year.

In this model, reindeer population is described by a logistic equation coupled to a variable carrying-capacity. Population growth is limited by the carrying-capacity of the island. However, it may be argued that the population dynamics of reindeer may also be described by resource-herbivore model based on a variant of the classic Lotka-Volerra model.

\subsection{Our model}

Our proposed model is a resource-herbivore model expressed as a Lotka-Volterra type interaction model,

$$
\begin{aligned}
\frac{d L}{d t} & =r L\left(1-\frac{L}{L_{0}}\right)-e L N \\
\frac{d N}{d t} & =\eta e L N-d N .
\end{aligned}
$$

In these equations $L$ and $N$ represent the abundance of lichen (resource) and reindeer (herbivore) respectively. The quantity $L_{0}$ is the maximum amount of lichen biomass that St. George Island can sustain and represents the initial abundance at the time the reindeer are introduced to the island. The parameter $r$ represents the intrinsic growth rate of lichen in the absence of reindeer, whereas the second term represents a density-dependent consumption rate. The parameter $e$ represents the intensity of consumption of lichen by the reindeer, which is interpreted as the unit of biomass of lichen consumed by a reindeer per unit time. In the second equation, $\eta$ represents the conversion efficiency - the efficiency at which a reindeer converts the consumed lichen into energy to both maintain the herd and for reproduction. The unit for $\eta$ is number of reindeer per unit biomass of lichen. Finally, $d$ represents the mortality rate of reindeer, a combination of natural death and the possible light harvesting of the reindeer population.

Since the lichen regrowth is very slow compared to its consumption by the reindeer, the first term in equation (4) is negligible, resulting in the even simpler system 


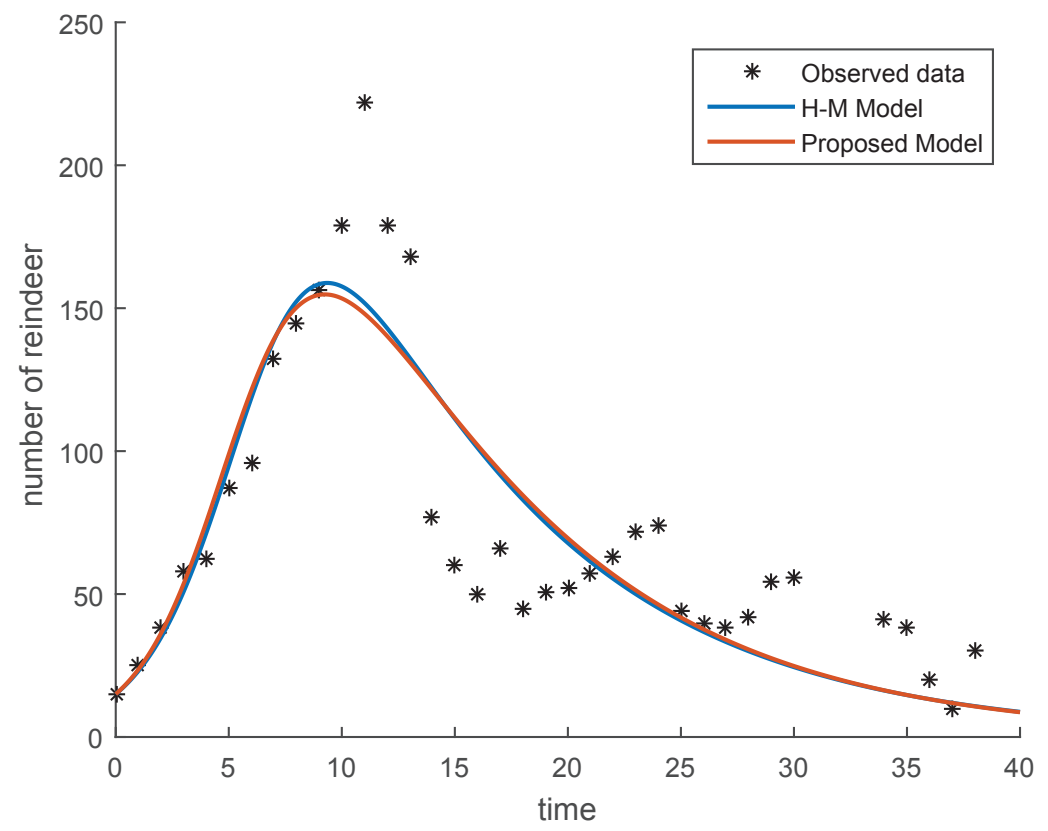

Figure 2. A comparison of the reindeer dynamics predicted by the proposed model and the H-M model.

$$
\begin{aligned}
\frac{d L}{d t} & =-e L N \\
\frac{d N}{d t} & =\eta e L N-d N
\end{aligned}
$$

The initial biomass of lichen in St. George Island was estimated as 4460 tons by Huzimura \& Matsuyama (1999). So, we will use $\left(L_{0}, N_{0}\right)=(4460,15)$ as an initial condition to solve the above system.

\section{RESULTS AND DiscuSSION}

All of the parameters $(e, \eta, d)$ were estimated using the built in MATLAB function fminsearch. It is an unconstrained optimisation algorithm that minimizes an error functional being the sum of the squared difference between model and data over the parameter space. The estimated parameter values are $e=0.0020$, $\eta=0.0631$ and $d=0.1083$. Figure 2 shows a comparison between the H-M model and our model with respective optimal parameter values for each model. Figure 3 compares between the carrying capacities estimated by H-M model and proposed model. Since the proposed model does not have any explicit term of carrying capacity, it is estimated by the quantity $\eta L$ where $L$ is the lichen biomass and $\eta$ is the conversion efficiency of lichen. Both of the models have generated almost the same population dynamics, even though the our model did not include any explicit form of the carrying-capacity. The initial almost unbounded growth of reindeer was inhibited by the heavy consumption of the lichen resource by the reindeer in subsequent years. The consequence of a slow replenishment rate of the lichen results in the decline of the lichen and reindeer abundances.

The system (6) and (7) can be further reduced by considering the rate of change of $N$ with respect to $L$,

$$
\frac{d N}{d L}=-\eta+\frac{d}{e L}
$$

which upon integration yields,

$$
N+\eta L=N_{0}+\eta L_{0}-\frac{d}{e} \ln \left(\frac{L_{0}}{L}\right) .
$$




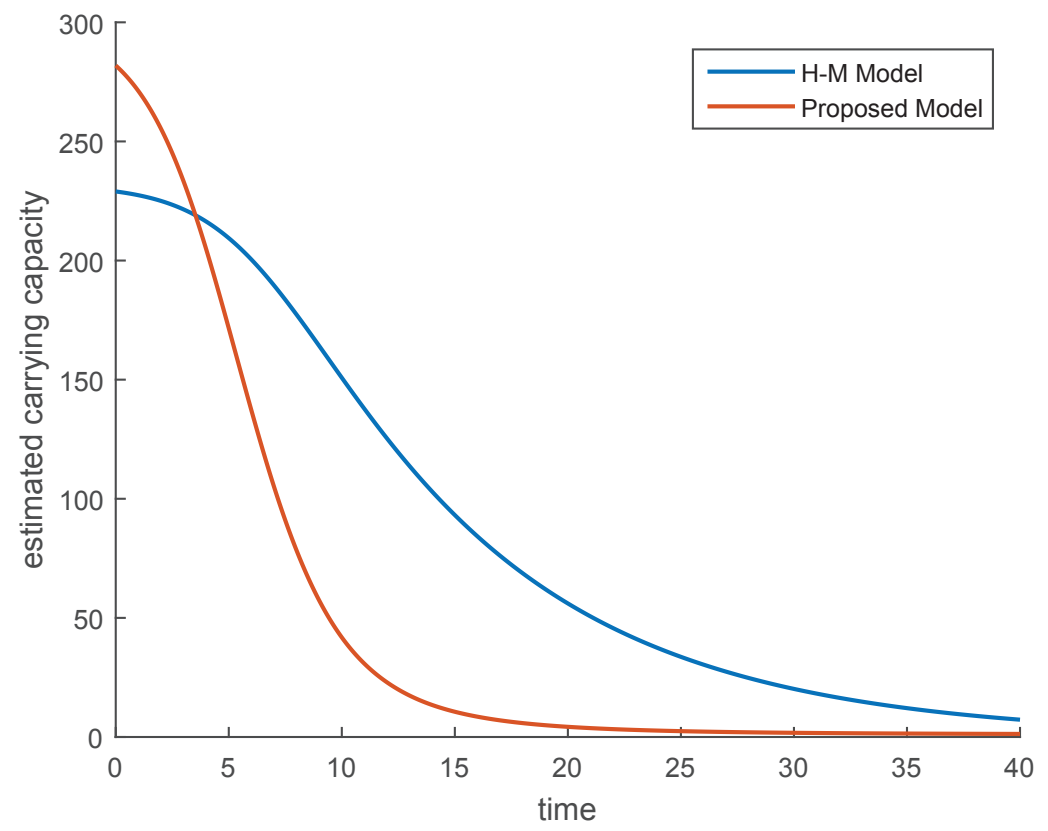

Figure 3. The estimated carrying capacity (the maximum number of reindeer the island can support) predicted by the proposed model and the H-M model.

It is clear that the quantity, $e(N+\eta L)-d \ln L$, is time-independent and thus conserved.

Solving for $\eta L$ and substituting into (7) we get,

$$
\frac{d N}{d t}=r(t) N(t)\left(1-\frac{N(t)}{K(t)}\right)
$$

where

$$
r(t)=e\left(N_{0}+\eta L_{0}\right)-d \ln \left(\frac{L_{0}}{L}\right)-d
$$

and $K(t)=r(t) / e$. Here, $r(t)$ and $K(t)$ represent the time-dependent growth rate of reindeer and carrying capacity of the island. Both the growth rate of reindeer and the carrying capacity of the island decreases over time because of the shortage of lichen.

\section{Conclusion}

The introduction of an invasive species in a confined environment can have a detrimental effect on the overall environment and associated species that live in it. The growth of the reindeer on the Pribilof Islands in the early years after their introduction was consistent with the purpose of introducing the herd in the first place to provide an alternative source of meat for people in the seal fur trade. However, it was not sustainable. As the herd grew in size it began to deplete the abundance of lichen and within 40 years the herd population was decimated.

In this paper we proposed a Lotka-Volterra type model and compared it to the H-M model, representing quite different approaches to modeling the dynamics of the reindeer population. Interestingly, both models give very similar dynamics, possibly suggesting that population dynamics in a confined environment with a depleting resource can give rise to non-unique models. Therefore, the choice of model may depend on the ease of experimentally determining the relevant parameters in the model. 


\section{REFERENCES}

Charles, H. \& Dukes, J. S. (2007), 'Impacts of invasive species on ecosystem services', Biological invasions pp. 217-237.

Clavero, M. \& García-Berthou, E. (2005), 'Invasive species are a leading cause of animal extinctions', Trends in ecology \& evolution 20(3), 110.

Elton, C. S. (2000), The ecology of invasions by animals and plants, University of Chicago Press.

Holmes, T. P., Aukema, J. E., Von Holle, B., Liebhold, A. \& Sills, E. (2009), 'Economic impacts of invasive species in forests', Annals of the New York Academy of Sciences 1162(1), 18-38.

Huzimura, R. \& Matsuyama, T. (1999), 'A mathematical model with a modified logistic approach for singly peaked population processes’, Theoretical Population Biology 56(3), 301-306.

Klein, D. R. \& Shulski, M. (2011), 'The role of lichens, reindeer, and climate in ecosystem change on a Bering Sea Island', Arctic pp. 353-361.

Pejchar, L. \& Mooney, H. A. (2009), 'Invasive species, ecosystem services and human well-being', Trends in ecology \& evolution 24(9), 497-504.

Rhymer, J. M. \& Simberloff, D. (1996), 'Extinction by hybridization and introgression', Annual Review of Ecology and Systematics 27(1), 83-109.

Sakai, A. K., Allendorf, F. W., Holt, J. S., Lodge, D. M., Molofsky, J., With, K. A., Baughman, S., Cabin, R. J., Cohen, J. E., Ellstrand, N. C. et al. (2001), 'The population biology of invasive species', Annual review of ecology and systematics 32(1), 305-332.

Scheffer, V. B. (1951), 'The rise and fall of a reindeer herd', The Scientific Monthly 73, 356-362.

Stein, B. A., Kutner, L. S. \& Adams, J. S. (2000), Precious heritage: the status of biodiversity in the United States, Oxford University Press on Demand.

Vitousek, P. M., Antonio, C. M., Loope, L. L. \& Westbrooks, R. (1996), 'Biological invasions as global environmental change', American scientist 84(5), 468.

Williamson, M. (1996), Biological invasions, Vol. 15, Springer Science \& Business Media. 